\title{
Measuring Consumer Attitude towards Soft Drinks: An Empirical Study on Selected Brands in Bangladesh
}

\author{
Meher Neger $^{1}$, Bulbul Ahamed ${ }^{2}$, Khaled Mahmud ${ }^{3}$ \\ ${ }^{I}$ Department of Marketing, Comilla University, Bangladesh \\ ${ }^{2}$ Department of CSE, Northern University Bangladesh \\ ${ }^{3}$ Institute of Business Administration, University of Dhaka, Bangladesh
}

*Corresponding Author: Khaled Mahmud, Institute of Business Administration, University of Dhaka, Bangladesh

\begin{abstract}
In today's competitive business environment, consumers are exposed to a large number of brand choice alternatives. This study examines consumer attitude towards the four popular soft drinks brands: 7 up, Sprite, Coca-Cola, and Pepsi by using Fishbein's Multi-attribute Attitude Model. These four most popular soft drinks brands have been taken into consideration for analyzing and understanding consumer attitudes. The result shows that consumers have the highest positive attitude towards 7up. Coca-cola has the second topmost position among the selected brands by samples, and then Pepsi and Sprite are in the third and fourth position respectively. Five salient beliefs (price, brand image, taste, availability, and flavour) have been selected from pretest and were used to predict consumers' attitude. Results of the study may be helpful for academicians, soft drinks companies, marketing managers and other applied researchers to depend on the attitude construct for improving the quality of soft drinks and developing marketing strategies.
\end{abstract}

Keywords: Consumer attitude, Fishbein's Multi-attribute Attitude Model, Salient beliefs

\section{INTRODUCTION}

Concept of consumer attitude is one of the most important concepts in the study of consumer behavior. Many firms are spending millions of dollars researching consumer's attitude toward their products and brands. The term 'measuring consumer's attitude' is used to identify what types of feelings the consumers show on specific branded products. Attitudes are learned predisposition to behave in a consistently favorable or unfavorable way with respect to a given object. Attitudes are not overt behavior, rather covert or unobservable internal reactions (Kim, 2002). Consumers learn these attitudes over time by being exposed to the object directly or through receiving information about the object. Favorable attitude can be the cause of favorable buying decisions. It is related to the intention of buying a product. This study is conducted to find out the total attitude of consumers towards soft drinks items in Bangladesh and to see how these are influenced by the total attributes of the product. The consumers make decisions about the quality of products based on a systematic process of acquisition, evaluation and integration of product cues. A cue is defined as an informational stimuli available to the consumer before consumption (Monroe and Krishnan, 1976), and it can be intrinsic or extrinsic. Soft drinks item related intrinsic constructs are packaging, flavor, taste and extrinsic constructs are price, brand image, availability and so on. These features are important from marketing perspective as they can have different important influences on attitudes of consumers toward a product. With the help of overall attitude toward the product, marketers can implement appropriate marketing strategies to achieve market share. Multiple researchers have found a relationship between product quality and intrinsic/extrinsic cues.

However, after independence consumer attitude and food habit of Bangladeshi people has changed dramatically. Besides traditional food items, Bangladeshi consumers like to take Western food also after the 1980s. Different foreign food companies were established in Bangladesh. Beverage industry is one of them. Carbonated beverage entered into our market in the later part of 1980. At that time there were only few companies in Bangladesh. But by the change of time and western culture influences it's become very popular in Bangladesh. Soft drinks in a nonalcoholic beverage, sally 
carbonated, consisting of water that is soda water flavoring and a sweet syrup or artificial sweetener. By the year 2000 more than 12 Beverage companies are operating business in Bangladesh and most of them are foreign companies. As people of the third world country, consumers are very much price conscious but simultaneously they consider the quality of the product. The quality of the product can increase with adding intrinsic attributes as well as increasing the image of extrinsic attributes. The study has tried to measure the attitude of the consumer towards soft drinks items in Bangladesh on the basis of intrinsic and extrinsic cues. Information cues have also been analyzed in this study clearly.

The paper is organized as follows: Section1 focuses on introductory issues, Section 2 represents the statement of the problem, Section 3 reviews the literature relevant to attitude perception and competitiveness in the market, Section $\mathbf{4}$ analyzes the objectives of the study, Section $\mathbf{5}$ discusses the methodology of the study, Section 6 discusses the attitude measurement procedure, Section $\mathbf{7}$ depicts the findings of the study, Section $\mathbf{8}$ describes the recommendations and conclusion, finally, limitations of the study and future research direction are made in Section $\mathbf{9 .}$

\section{Problem Statement}

Attitude-behavior relationship is important to marketers because they theoretically summarize a consumer's evaluation of an object and represent positive or negative feelings and behavioral tendencies. At the same time the link between attitude and behavior can affect by other factors. Particularly, consumers' opinions and attitudes about the influencing factors of the product buying decisions making process, including the perceived attributes development impacts, environmental attitudes, affect and cognition level (feeling, thinking) and culturally adoption of the product have become problem for the country. The purchase decision of a consumer is different as it is lead by buying power, which can help the soft drinks companies and marketing planners for capturing the market share. Consequently, given the fact that there is limited empirical research of soft drinks and attitudes of consumers towards different brands of soft drinks in our country, this study is developed and empirically tests its relevant components from the perspectives of Bangladeshi consumers. Therefore, the information from this study may be helpful for planners and policy-makers to build more competitive brand in the market choice.

\section{LITERATURE REVIEW}

The review of literature can help a researcher to build up the conceptual framework about certain topics. Some selected reviews have been presented below to find out the specific research gaps.

William R. George (1999), objective was that factors responsible for brand preference in soft drink industry, increasing competition more, due to globalization is motivating many companies to base their strategies almost entirely on building brands. Brand preference means to compare the different brands and adopt for the most preferred brand. This brand preference is influenced by various factors. In the identification of factors affecting the brand preference, it was concluded that Brand persona is the most effective factor that affects the brand preference. This Brand persona deals with the personality aspects or the external attributes of brand, thus it can be said that consumer prefer any brand by looking at the external attributes of a brand.

Stephen Daniells (2008), objective was that to measure the quality of the soft drink and preference. Four factors were identified for the formulation: four color intensities, three flavorings, two label types (soft versus hard), and two pack sizes (standard versus oversize). By using both quantitative (hedonic testing) and qualitative (focus group) approaches, the researchers found that the main factors which drive consumer preference for this concept are color intensity and flavoring. Indeed, color intensity accounted for $43 \%$ and flavor $32 \%$ of the consumers' overall liking. "Pack size and label type" are taken into account by the consumer to a lesser extent. The methodology of a qualitative screening associated to a conjoint analysis on relevant sensory attributes has shown good performances to fit consumers' exception: it has now to be reproduced, as every brand concept and product is a unique combination designed for a specific consumer group.

N. Meher \& Sunny (2013), objective was that to determine the factors influencing on brand loyalty of soft drinks. As the stimuli of soft drinks was selected. Pearson correlation and multiple regression 
models were used to examine the variables and to test the hypotheses; where the perceived quality, price, brand trust and promotion were the independent variables of the study. The empirical results demonstrated that perceived quality, price, brand trust and promotion have significant influence on consumers' brand loyalty of soft drinks in Bangladesh.

H. Muzakkeerul \& Alam's (2009) objective was that to measure consumers' attitudes for bottle mineral water in Bangladesh. As the stimuli, Mum, Fresh and Spa were selected. Fishbein's Multiattribute attitude model was used to measure the variables. The result of the study is that people have the highest positive attitude towards Mum and then Spa and Fresh are in the second and third position respectively. Five salient beliefs (price, brand image, packaging, availability and taste) have been selected from pretest and were used to predict consumers' attitude.

After reviewed some related literatures it is clear that in all articles discussed about different branded soft drinks and their attention toward beverage items. Though adequate research has been undertaken to measure consumer attitudes and to find out factors affecting consumer attitudes, basing on a country or continent, there is no such direct and solo research as this study that is based on a perspective of Bangladeshi consumers. Again, they only research on why the consumers react and which factors affect consumer attitude towards soft drinks in Bangladesh or other countries. So, this study tries to fill up the gap by using intrinsic and extrinsic attributes of soft drinks for measuring consumers' attitude towards soft drinks items. With this study, soft drinks industries may be able to find out their loopholes and thereby take necessary steps to improve their product's attributes, services and benefits and to compete in better ways.

\section{OBJECTIVES OF THE STUDY}

The main objective of the study is to measure consumer's attitude towards soft drinks in Bangladesh. The specific objectives of this study is, firstly, to find out the different attributes which are considered by Bangladeshi consumers while purchasing soft drinks, secondly, to measure the attitudes of consumers towards soft drinks based on Fishbein's Multi-attributes Attitude Model, and finally to highlight some suggestions to form positive attitude of Bangladeshi consumers towards soft drink items and to protect the market share by soft drinks companies in the competitive market.

\section{Methodology of The Study}

This study examines how consumers form attitude towards soft drinks brands based on the evaluation of the salient beliefs of the consumers. The survey approach is used for this study. Details of the pretests, sample respondents, types of data, data collection method and data analysis procedures are discussed below.

\subsection{Pretest 1}

The purpose of conducting the first pretest is to select the attributes which are considered by the consumers of soft drinks. This information cultivated among 120 respondents. When asked about the attributes of the soft drinks items that are basically considered for the study, they mentioned 10 attributes. Those having up to $50 \%$ and above have been selected for the convenience of the study. The following table shows the attributes that are considered by the consumer while purchasing soft drinks items.

Table1. Consumers' opinion on different attributes of soft drinks in Bangladesh

\begin{tabular}{|c|c|c|c|c|}
\hline No. & Attributes' Name & T.R. & T.R.D & $\%$ \\
\hline 1 & Price & 120 & 115 & 95.83 \\
\hline 2 & Brand Image & 120 & 90 & 75 \\
\hline 3 & Taste & 120 & 85 & 70.83 \\
\hline 4 & Availability & 120 & 70 & 58.33 \\
\hline 5 & Flavour & 120 & 65 & 54.17 \\
\hline 6 & Advertisement & 120 & 52 & 43.33 \\
\hline 7 & Packaging & 120 & 42 & 35 \\
\hline 8 & Size Variety & 120 & 40 & 33.33 \\
\hline 9 & Date of Expire & 120 & 35 & 29.17 \\
\hline 10 & Ingredients & 120 & 30 & 25 \\
\hline
\end{tabular}

$T R=$ Total Respondents, TRD = Total Respondents' Response 
Source: Field Investigation

From table 1, it is found that price, brand image, taste, availability and flavor are opined by $95.83 \%$, $75 \%, 70.83 \%, 58.33 \%$, and $54.17 \%$ respondents respectively. So, those five attributes bear up to $50 \%$ and above have been selected for the convenience of the study. Among the five attributes two intrinsic and three extrinsic are considered for final study.

\subsection{Pretest 2}

The purpose of conducting the second pretest is to select brands of soft drinks which are available in Bangladesh market. Among these, the brands having 50\% or above response of total respondents have been selected for the convenience of the study. The information has been collected from 120 respondents where approximately $60 \%$ are male and rest of the $40 \%$ are female. When the respondents were asked about the different brands of soft drinks, the name of 10 brands came to their mind at that moment. The following table shows the brand names of soft drinks that are considered by the consumers:

Table2. Consumers' opinion on different brands of soft drinks which are available in Bangladesh market

\begin{tabular}{|c|c|c|c|c|}
\hline No. & Brands' Name & T.R. & T.R.D & $\%$ \\
\hline 1 & 7 up & 120 & 110 & 91.67 \\
\hline 2 & Sprite & 120 & 105 & 87.50 \\
\hline 3 & Coca- Cola & 120 & 90 & 75 \\
\hline 4 & Pepsi & 120 & 60 & 50 \\
\hline 5 & Merinda & 120 & 45 & 37.5 \\
\hline 6 & Fanta & 120 & 42 & 34.17 \\
\hline 7 & Mojo & 120 & 41 & 33.33 \\
\hline 8 & Clemon & 120 & 35 & 29.17 \\
\hline 9 & Mountain Dew & 120 & 33 & 27.5 \\
\hline
\end{tabular}

$T R=$ Total Respondents, TRD = Total Respondents' Response

Source: Field Survey

From table 2, it is found that 7up, Sprite, Coca-Cola and Pepsi have got the highest importance, that means those brands bearing up to $50 \%$ and above have been selected for the convenience of the study.

\subsection{Sample Respondents}

Since sampling frame of the respondent is unavailable, probability sampling method for the research purpose is not appropriate. So, for time and budget constraints, the data have been collected on the basis of convenience sampling method with 200 desired sample sizes. Total 200 respondents who are directly influenced for using soft drinks are selected as sample respondents in this study. The respondents of the study consisted of the various aged consumers of soft drinks in Bangladesh. The study was confined with the soft drinks consumers of Dhaka and Comilla City Corporation areas. Two areas have been selected because time and cost were important considerations for such decision. A total of 225 questionnaires were distributed among the general people who were the target respondents of this study. 205 respondents were received of which 200 were complete and useable. So, 200 respondents were selected as a sample of the study. Besides, 120 respondents provided their opinions for pretesting questionnaire.

\subsection{Types of Data}

In order to achieve the specific objectives of the study, primary and secondary sources of data are used. The relevant primary data have been collected from the respondents directly through a set of structured questionnaires. The majority of the secondary data have been collected from articles, published books and websites on soft drink industry of Bangladesh.

\subsection{Data Collection Method and Procedures}

Data have been collected from general public and students through a set of structured questionnaires. In the surface page of the questionnaire, the purpose of the study is well described. After the surface 
page of the questionnaire, the respondents are asked to turn the page including information regarding the attributes of individual brands of soft drinks those are available in Bangladesh market. To measure the overall evaluation (ei) regarding the selected attributes of the specific brand rating scale ranging from Extremely Good to Extremely Bad (+3 -3) has been used and the respondents were asked to encircle the point to express their opinion. The respondents are also asked through the Seven point Likert Scale ranging from 7 indicates Very Strongly Believe, and 1 indicates Very Strongly Disbelieve to know how strongly they believe that the individual brand contains the said attributes.

\subsection{Data Analysis Procedures}

Simple statistical tools have been used to analyze the data. Statistical tool including percentage method has been used here. Data on demographic variables- gender, age and highest academic achievement were processed and reported through descriptive analysis. The opinion of the respondents has been analyzed in the light of the analysis procedures used by Fishbein's for measuring attitude of consumers towards objects.

\section{Attitude Measurement Procedure}

Martin Fishbein's model has been established as the most influential tool for analyzing the consumer's attitude. This multi-attribute attitude model focuses on consumer's belief about multiple product attributes which are considered as a useful tool for investigating attitude formation and prediction attitude. Simply stated, people tend to like the objects that are associated with "good" characteristics and dislike the objects which they believe have "bad" attributes. In Fishbein's multi-attribute model, overall attitude towards an object is a function of two factors: the strengths of the salient beliefs associated with the object and the evaluation of those beliefs. Formally, the model proposes that:

Ao $=\sum_{i=1}^{n}$ biei

Where,

Ao $=$ Attitude towards the object

$b i=$ Strength of the belief that the object has attributed (i),

$e i=$ The evaluation of the attribute (i),

$n=$ The number of the salient attributes.

This multi-attribute attitude model accounts for the integration process through which the product or service knowledge (the evaluations and strength of salient beliefs) is combined to form an overall evaluation of attitude (Fishbein, 1963).

\section{FINDINGS AND ANALYSIS}

The study basically intends to find out the attributes that affect attitude towards soft drinks in Bangladesh. It also gives an insight into how different attributes affect attitude in general.

\subsection{Respondents Demographic Data}

The analysis and findings of the respondents' demographics are shown in table 03 through the frequency distribution method.

Table3. Respondents' demographic information

\begin{tabular}{|c|c|c|}
\hline \multicolumn{3}{|c|}{ Gender } \\
\hline Characteristics & Frequency & Percent \\
\hline Male & 120 & 60 \\
\hline Female & 80 & 40 \\
\hline Total & 200 & 100 \\
\hline
\end{tabular}

\begin{tabular}{|c|c|c|}
\hline \multicolumn{2}{|c|}{ Age } & Percent \\
\hline Characteristics & Frequency & 20 \\
\hline Less than 18 & 40 & 40 \\
\hline $18-30$ & 80 & \\
\hline
\end{tabular}


Measuring Consumer Attitude towards Soft Drinks: An Empirical Study on Selected Brands in Bangladesh

\begin{tabular}{|c|c|c|}
\hline $31-45$ & 46 & 23 \\
\hline 46 0r older & 34 & 17 \\
\hline Total & 200 & 100 \\
\hline \multicolumn{3}{|c|}{ Education Level } \\
\hline Characteristics & Frequency & Percent \\
\hline S.S.C & 30 & 15 \\
\hline H.S.C & 50 & 25 \\
\hline Graduate & 76 & 38 \\
\hline Post Graduate & 44 & 22 \\
\hline Total & 200 & 100 \\
\hline
\end{tabular}

Source: Field Investigation

Out of 200 respondents of the study, majority of the respondents $(60 \%)$ were male, where as only $40 \%$ were female. About $20 \%$ of the respondents were aged less than 18 years and 40 percent were aged between $18-30$ years. $23 \%$ and $17 \%$ respondents were respectively $31-45$ and 46 or older aged. The education level shows that 76 and 44 respondents were in graduate and post-graduate level respectively. 25\% (50 respondents) were in H.S.C level and only 15\% (30 respondents) were in S.S.C level of education.

\subsection{Results of Fishbein's Multi-attribute Attitude Model}

Strength of belief (bi) is the perceived probability of association between an object and its relevant attribute. This belief was measured by having consumer rate in probability of association for each of their salient belief (Table: o4). The belief associated with belief evaluation (ei) that reflects how favorably consumers perceived the attributes (Table 04). It is clear from the table that the attitude towards soft drinks on the basis of Fishbein's Multi-attribute Attitudes (Ao) model are; Ao for 7up is $\mathrm{X}_{7 \text { up }}=20.26$, Coca Cola is $\mathrm{Xco}=8.6$, Ao for Pepsi is Xpe $=7.73$, and Ao for Sprite is Xsp $=6.73$ (table 04).

The findings suggest that $X_{7 u p}$ is viewed as the topmost favorable position because it received total (eibi) 20.26 on all desired attributes. Xco has second topmost position among the selected brands by samples, like these "Pepsi" and "Sprite" place the position third and fourth respectively based on overall attitude towards object. From the Fishbein's model, overall position of the consumers' attitude towards the individual object have been found on the basis of different attributes.

Table4. Consumers' overall evaluations (ei) and strengths of beliefs (bi) for different brands of soft drinks based on different attributes.

\begin{tabular}{|l|l|l|l|l|l|l|l|l|l|l|l|l|}
\hline \multirow{2}{*}{ Attributes } & \multicolumn{3}{|l|}{ lup } & \multicolumn{3}{l|}{ Sprite } & \multicolumn{3}{l|}{ Coca-Cola } & \multicolumn{2}{l|}{ Pepsi } \\
\cline { 2 - 14 } & ei & bi & eibi & ei & bi & eibi & ei & bi & eibi & ei & bi & eibi \\
\hline Price & 0.93 & 4.95 & 4.60 & 0.36 & 4.68 & 1.68 & 0.67 & 4.6 & 3.08 & 0.5 & 3.52 & 1.76 \\
\hline $\begin{array}{l}\text { Brand } \\
\text { Image }\end{array}$ & 0.52 & 5.53 & 2.87 & 0.39 & 4.35 & 1.69 & 0.18 & 3.8 & 0.68 & 0.34 & 3.73 & 1.27 \\
\hline Taste & 0.34 & 4.35 & 1.48 & 0.28 & 4.2 & 1.18 & 0.7 & 3.37 & 2.36 & 0.23 & 4.0 & 0.92 \\
\hline Availability & 2.21 & 3.53 & 7.80 & 0.34 & 4.24 & 1.44 & 0.58 & 3.53 & 2.04 & 0.29 & 3.35 & 0.97 \\
\hline Flavour & 0.74 & 4.75 & 3.51 & 0.23 & 3.2 & 0.74 & 0.1 & 4.4 & 0.44 & 0.67 & 4.2 & 2.81 \\
\hline Ao-Zeibi & & & 20.26 & & & 6.73 & & & 8.6 & & & 7.73 \\
\hline
\end{tabular}

Source: Field Survey

(Note: Number of Respondents 200)

According to positions: $\left(\mathrm{Ao}_{7 \mathrm{up}}=20.26, \mathrm{Ao}_{\mathrm{Co}}=8.6, \mathrm{Ao}_{\mathrm{Pe}}=7.73, \mathrm{Ao}_{\mathrm{Sp}}=6.73\right)$

\section{RECOMMENDATIONS AND CONCLUSION}

Considering the above analysis and discussion,the present study attempts to outline some suggestions for creating positive attitude of consumers towards soft drinks in Bangladesh. Such as- 
i. Companies should put more efforts in monitoring and creating the brand image and taste ofsoft drinks and introducing new flavoured drinks aiming at creating positive attitude towards soft drinks.

ii. It may be said that as the marketers are ever changing in relation to changing consumers attitude, so for gaining the competitive advantage in the market place in the long run, the marketers should take various marketing strategies on the basis of customization.

iii. The soft drinks companies can follow all possible attitude- change strategies which are: to add new salient belief about the attitude objects-ideally one with a positive to increase the strength of an existing positive to increase evaluation of a strongly held belief to make an existing belief more salient.

Conclusively, the study has employed consumers brand attitude measurement based on Fishbein's Multi-attributes Attitude Model for soft drinks in Bangladesh. This model applied for four brands of soft drinks which are widely used in Bangladesh. Considerable five attributes have been selected as determinant of brand choice. The result reported here strongly supports that the brand attitude is related to attitude measurements based upon beliefs about and relative importance of product-specific attributes.7up bears the highest attitude of consumers. Coca -Cola is the second most popular brand and the Sprite the lowest popular brand in Bangladesh as per the opinions of the consumers. The findings highlight the need to gain an understanding of the separate impact of both intrinsic an extrinsic attributes and their contribution to the brand preference individually. Finally, the measurement of attitude towards soft drinks and top priority marketing issues in recent years, as evidence by the growing literature on the subject.

\section{LiMitATIONS AND FUtURE RESEARCH}

There are some limitations of this study that future research should continue to test and refine. The study reveals that five attributes are considered for measuring consumers attitude towards soft drinks, which have five strengths of belief (bi) that always may not be true. There might be more attributes, which could influence the consumers for purchasing soft drinks like model variation,advertisement etc.

Therefore, further research may be conducted to assess product benefits and risks of each feature of soft drinks considering more attributes including exogenous variables. Besides, the major limitation of this study is that the study attempts to consider only four brands of soft drinks. It would have been more representative if the total number of brands of soft drinks could have been taken under this study. But it is not possible due to financial and time constraints. It is the opportunity of the future researchers to overcome these shortcomings Moreover, we used only Martin Fishbein'sMultiattribute Attitude Model for measuring consumers attitude in this field, so other researchers have the options to measure the consumers'attitud toward the object and can also use the other techniques in sampling and measuring attitudes.

\section{REFERENCES}

[1] Alam, Md. Jahangir and N. Meher, (2009), "Measuring Consumer Attitude towards Beautification Products: A Study on Some Selected Brands in Bangladesh”. Journal of Business and Technology (Dhaka), Vol.4, issue-2, (July-December), pp. 59-69.

[2] D. Stephen, (2008), "Soft Drink Quality and Preference". European Journal of Marketing, Vol.27, Issue7, pp. 25-35. edupedia.educarnival.com/the-current-market-scenario-of-beverage-industry

[3] Fishbein, Mi (1963), "An Investigation of the Relationship between Beliefs about an Object and the Attitude towards the Object". Human Relations, Vol.16, pp. 233-240.

[4] H. Muzakkeerul and Alam (2009), "Measuring Consumers' Attitudes for Bottled Mineral Water in Bangladesh: An Empirical Study on Mum, FRESH, and SPA", Journal ofBusiness and Technology (Dhaka), Vol.iv, Issue-i, (January-June), pp. 130-143.

[5] Mia Md. Abdul Hunnan (1999), "Measurement of Brand Attitudes of Brand Loyal of Detergent Powder and their Advertising Implication". Dhaka University Journal of Business Studies, Vol.20, No.2, pp. 265292. 
[6] Monroe, K. B and Krishnan, R. (1976), “ The Effect of Price on Subjective Evaluations”, in Jacoby, J, and Olson, J. (Eds).Perceived Quality, Lexington Books, Lexington, MA.

[7] N. Meher and Sunny, (2013), "Factors Influencing on Brand Loyalty: An Empirical Study on Soft Drinks in Bangladesh”. Rabindro Journal, Vol.15, No.1, (October), pp. 201-214.

[8] William R. G., (1999), "Brand Preference in Soft Drink Sector". Advances in consumer Research, Vol.26, pp. 485-490.

[9] Zeithamal, V. A., (1988), “Consumer Perceptions of Price, Quality and Value: A Means-End-Model and Synthesis of Evidence". Journal of Marketing, Vol.52, Issue-3, pp.2-22.

\section{AUTHORS' BIOGRAPHY}

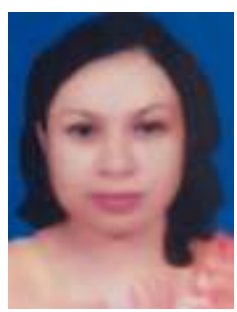

Meher Neger has been conducted her Ph.D in Brand Switching Behavior at University of Dhaka, Bangladesh under the Department of Marketing. She obtained her M.Phil in Consumer Behavior at University of Rajshahi, Bangladesh. She had her MBA (Marketing) from University of Rajshahi, Bangladesh. She was graduated from the said University. She was awarded gold medal in her graduate level for excellent academic performance. She was also awarded fellowship for M.Phil program from University of Rajshahi, Bangladesh. She previously worked as a Senior Lecturer in different private Universities (Bangladesh University, Northern University and ASA University) in Bangladesh. Now she is working as an Assistant Professor, Department of Marketing, Comilla University, Bangladesh. She has published her articles in different journals of USA, India, United Arab Emirates and Bangladesh.

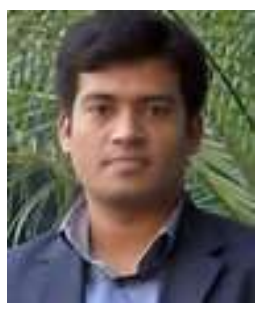

Bulbul Ahamed was born in Munshiganj, Bangladesh in 1982. He had his M.Sc. in Computer Science and Engineering at United International University, Bangladesh. He obtained his B. Sc. in Computer Science and Engineering and MBA (major in MIS \& Marketing) from Northern University Bangladesh. He is now working as an Assistant Professor in the Department of Computer Science and Engineering, Northern University Bangladesh. His research interests include Speech Recognition, Artificial Intelligence, Neural Network and E-Commerce. He has published his articles in different journals and conferences of USA, UAE, Pakistan, and Bangladesh. He has published one book: "Information and Communication Technology" for Higher Secondary Education, Approved by National Curriculum \& Textbook Board, Bangladesh.

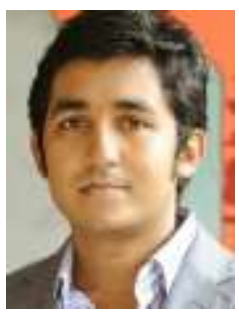

Khaled Mahmud is Assistant Professor at the Institute of Business Administration (IBA), University of Dhaka. He is a Fulbright business fellow and received his MBA from Bentley University, Massachusetts, USA. Prior to that, he completed his Masters of Business Administration in marketing form Institute of Business Administration (IBA), University of Dhaka. He completed his under-graduation in Computer Science and Engineering (CSE) from Bangladesh University of Engineering and Technology (BUET). Prior to joining IBA as a fulltime faculty, he worked in Standard Chartered Bank in Managerial position. He has a very diversified research portfolio. He published articles related to IT, marketing, finance, human resources, business strategy and social sciences.

Citation: Meher Neger et al. "Measuring Consumer Attitude towards Soft Drinks: An Empirical Study on Selected Brands in Bangladesh." International Journal of Managerial Studies and Research, vol 5, no. 10, 2017, pp. 1-8. doi:http://dx.doi.org/10.20431/2349-0349.0510001.

Copyright: (C) 2017 Authors. This is an open-access article distributed under the terms of the Creative Commons Attribution License, which permits unrestricted use, distribution, and reproduction in any medium, provided the original author and source are credited. 